Cite this: Phys. Chem. Chem. Phys. 2014, 16, 7850

Received 16th January 2014, Accepted 24th February 2014

DOI: 10.1039/c4cp00234b

www.rsc.org/pccp

\section{A rational design for the selective detection of dopamine using conducting polymers}

\author{
Georgina Fabregat, ${ }^{a b}$ Jordi Casanovas, ${ }^{c}$ Edurne Redondo, ${ }^{a}$ Elaine Armelin*ab and \\ Carlos Alemán*ab
}

Poly(N-methylpyrrole) (PNMPy), poly(N-cyanoethylpyrrole) (PNCPy) and poly(3,4-ethylenedioxythiophene) (PEDOT) films have been prepared using both single and two polymerization steps for the selective determination of low concentrations of dopamine, ascorbic acid and uric acid in tertiary mixtures. Analysis of the sensitivity and resolution parameters derived from the electrochemical response of such films indicates that PEDOT is the most appropriate for the unambiguous detection of the three species. Indeed, the performance of PEDOT is practically independent of the presence of both gold nanoparticles at the surface of the film and interphases inside the film, even though these two factors are known to improve the electroactivity of conducting polymers. Quantum mechanical calculations on model complexes have been used to examine the intermolecular interaction involved in complexes formed by PEDOT chains and oxidized dopamine, ascorbic acid and uric acid. Results show that such complexes are mainly stabilized by $\mathrm{C}-\mathrm{H} \ldots \mathrm{O}$ interactions rather than by conventional hydrogen bonds. In order to improve the sensitivity of PEDOT through the formation of specific hydrogen bonds, a derivative bearing a hydroxymethyl group attached to the dioxane ring of each repeat unit has been designed. Poly(hydroxymethyl-3,4-ethylenedioxythiophene) (PHMeDOT) has been prepared and characterized by FTIR, UV-vis spectroscopy, cyclic voltammetry, scanning electron microscopy and atomic force microscopy. Finally, the performance of PHMeDOT and PEDOT for the selective detection of the species mentioned above has been compared.

\section{Introduction}

$\pi$-Conjugated conducting polymers (CPs), such as polypyrrole (PPy) and polythiophene (PTh) derivatives, have been a subject of intense research due to their interesting electronic and optical properties. ${ }^{1-3}$ Among PTh derivatives, poly(3,4-ethylenedioxythiophene) (PEDOT) deserves special attention because of a combination of properties. This $\mathrm{CP}$, which was originally described by researchers at the Bayer company, exhibits moderate band gap, low oxidation potential, high conductivity, good optical transparency, and exceptional environmental stability. ${ }^{4-6}$ PEDOT attracted considerable interest, and many electronic applications based on these properties were rapidly developed (e.g. as an electrode material in supercapacitors, a hole injection layer in organic light-emitting diodes and solar cells). ${ }^{7-10}$ Recently, some potential biotechnological applications

\footnotetext{
${ }^{a}$ Departament d'Enginyeria Química, E. T. S. d'Enginyers Industrials, Universitat Politècnica de Catalunya, Diagonal 647, 08028 Barcelona, Spain. E-mail: elaine.armelin@upc.edu, carlos.aleman@upc.edu

${ }^{b}$ Center for Research in Nano-Engineering, Universitat Politècnica de Catalunya, Campus Sud, Edifici C', C/Pasqual i Vila s/n, Barcelona E-08028, Spain ${ }^{c}$ Departament de Quimica, Escola Politècnica Superior, Universitat de Lleida, c/ Jaume II $n^{\circ}$ 69, Lleida E-25001, Spain
}

of this CP have also been proposed (e.g. as a biosensor for the detection of specific nucleotide sequences, ${ }^{11}$ neurotransmitters ${ }^{12}$ and amino acids, ${ }^{13}$ a biocondenser with bactericide properties, ${ }^{14,15}$ a bioactive substrate for cell adhesion and proliferation ${ }^{16,17}$ ).

CPs have been successfully used to detect dopamine (DA) ${ }^{18-23}$ which is an important neurotransmitter of catecholamine in the human brain. ${ }^{24}$ The very low concentration of DA in the extracellular fluid ${ }^{25}$ provides a huge challenge for the detection of this analyte. The temporal fluctuation of the DA concentration in the human brain has a critical effect on several neurological disorders, such as Harrington's disease and Parkinson's disease. ${ }^{25}$ In recent studies we detected DA concentrations significantly lower than the synaptic one $(1.6 \mathrm{mM})$ using PPy derivatives. ${ }^{18,19}$ More specifically, poly( $N$-methylpyrrole) and poly( $N$-cyanoethylpyrrole), hereafter denoted PNMPy and PNCPy, respectively, deposited on glassy carbon electrodes were found to be highly sensitive to the DA concentration, presenting a very fast response even when the concentration of neurotransmitter is very low. ${ }^{18,19}$ Furthermore, such response was enhanced by adding gold nanoparticles (AuNPs) to PNMPy or PCNPy films (i.e. forming PNMPy/AuNP and PNCPy/AuNP composites), even though metallic nanoparticles were not essential for the sensing 
abilities of such CPs. Quantum mechanical calculations indicated that intermolecular $\mathrm{C}-\mathrm{H} \cdots \mathrm{O}$ interactions play a crucial role in the detection of DA using such two PPy derivatives. ${ }^{19}$ More recently, PEDOT and PEDOT/AuNP deposited on different types of electrodes were used for the selective determination of very low DA concentrations in the presence of uric acid (UA) and ascorbic acid (AA). ${ }^{20-23}$ It should be mentioned that DA, AA and UA coexist in extracellular fluids of the central nervous system and, therefore, the selective determination of these species is a major goal for the biomedical application of sensors.

Despite the accrued interest in the selective sensing of DA using electrochemical methods, the abilities of PPy and PTh derivatives mentioned above have not been compared yet. This seems a crucial requirement for the rational design of CPs with optimized sensing capacities. In this work we compare the sensing ability of PEDOT, PNMPy and PNCPy (Scheme 1) for the electrochemical detection of DA in tertiary mixtures with UA and AA. For this purpose, sensing templates based on these three CPs have been prepared by applying both single and two polymerization steps. Recent studies have evidenced that the electrochemical properties of CPs produced using multiple polymerization steps are significantly better than those of materials yielded through a continuous polymerization process, ${ }^{26}$ which was attributed to the existence of favorable interactions at the interfaces induced by the former procedure. Accordingly, the impact of such interactions on the sensing ability of CPs has been examined by comparing materials produced using a single continuous process (i.e. 1-CP, where $\mathrm{CP}=$ PEDOT, PNMPy or PNCPy) and two polymerization steps (i.e. 2-CP). On the other hand, the synergy between AuNPs and CPs has been ascertained by comparing the sensitivity and resolution of 1-CP and 2-CP sensors with those of composites prepared by coating the surface of $\mathrm{CP}$ films with AuNPs (i.e. 1-CP/AuNPs and 2-CP/AuNPs). Furthermore, quantum mechanical methods based on density functional theory (DFT) calculations have been applied to investigate the interactions involved in the binding between PEDOT and the oxidized analytes. Results have been compared with those reported for PNMPy and PNCPy. ${ }^{19}$ Overall of the results has been used to improve the selectivity and sensitivity of PEDOT by engineering some chemical modifications essentially oriented to enhance the binding between the CP and the analytes. Experimental development of such rational design has allowed us to identify a CP that has been proved to show optimized selectivity and sensitivity for the separation of DA, AA and UA in tertiary mixtures.

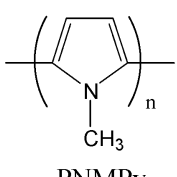

PNMPy

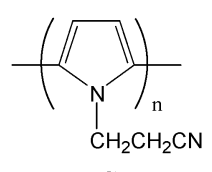

PNCPy

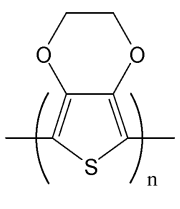

PEDOT
Scheme 1

\section{Methods}

\section{Materials}

3,4-Ethylenedioxythiophene (EDOT), $N$-methylpyrrole (NMPy), $\mathrm{N}$-(2-cyanoethyl)pyrrole (NCPy), acetonitrile, anhydrous lithium perchlorate $\left(\mathrm{LiClO}_{4}\right)$, DA hydrochloride (3-hydroxytyramine hydrochloride), AA (L-configuration, crystalline), UA (crystalline) and $\mathrm{HAuCl}_{4} \cdot 3 \mathrm{H}_{2} \mathrm{O}$ of analytical reagent grade were purchased from Sigma-Aldrich (Spain), while sodium citrate dehydrate was obtained from J. T. Baker. All chemicals were used without further purification. Phosphate buffer solution (PBS) $0.1 \mathrm{M}$ with $\mathrm{pH}=7.4$ was prepared as electrolyte solution by mixing four stock solutions of $\mathrm{NaCl}, \mathrm{KCl}, \mathrm{NaHPO}_{4}$ and $\mathrm{KH}_{2} \mathrm{PO}_{4}$. High-purity nitrogen was used for de-aeration of the prepared aqueous solutions.

\section{Synthesis of CPs}

PEDOT, PNMPy and PNCPy films were prepared by chronoamperometry (CA) under a constant potential of $1.40 \mathrm{~V}^{27-29}$ using a three-electrode two-compartment cell under nitrogen atmosphere (99.995\% in purity) at $25{ }^{\circ} \mathrm{C}$. A bare glassy carbon (GC) electrode with a diameter of $2 \mathrm{~mm}$ was used as a working electrode while a steel AISI 316 sheet with an area of $1 \mathrm{~cm}^{2}$ was employed as a counter electrode. The surface of the GC electrode was polished with alumina powder and cleaned by ultrasonication prior to the deposition of the polymer. The reference electrode was an $\mathrm{Ag} \mid \mathrm{AgCl}$ electrode containing a $\mathrm{KCl}$ saturated aqueous solution $\left(E^{\circ}=0.222 \mathrm{~V} v s\right.$. standard hydrogen electrode at $\left.25^{\circ} \mathrm{C}\right)$, which was connected to the working compartment through a salt bridge containing the electrolyte solution. All electrochemical experiments were conducted on a PGSTAT302N AUTOLAB potenciostat-galvanostat (Ecochimie, The Netherlands) equipped with the ECD module to measure very low current densities $(100 \mu \mathrm{A}-100 \mathrm{pA})$, which was connected to a PC computer controlled through the NOVA 1.6 software.

1-PEDOT, 1-PNMPy and 1-PNCPy films (i.e. CPs prepared using a single continuous polymerization step) were obtained using a $10 \mathrm{mM}$ monomer solution in acetonitrile with $0.1 \mathrm{M}$ $\mathrm{LiClO}_{4}$ and a polymerization time $\theta_{1-\mathrm{CP}}=6,10$ and $10 \mathrm{~s}$, respectively. The generation of 2-CP films was performed by applying two polymerization steps. In the first step, the working electrode was immersed in a cell filled with a $10 \mathrm{mM}$ monomer solution in acetonitrile with $0.1 \mathrm{M} \mathrm{LiClO}_{4}$ for a period of time $\left(\theta_{1}\right)$. After this, the polymerization was interrupted and the electrode coated with the first layer of CP was immersed in a fresh solution identical to the previous one during a period of time $\left(\theta_{2}\right)$. Accordingly, the total polymerization time for each 2-layered film is: $\theta_{2-\mathrm{CP}}=\theta_{1}+\theta_{2} \mathrm{~s}$. In order to obtain thin films, $\theta_{1}=\theta_{2}=3 \mathrm{~s}$ for 2-PEDOT and $\theta_{1}=$ $\theta_{2}=5 \mathrm{~s}$ for both 2-PNMPy and 2-PNCPy. Thus, $\theta_{1-\mathrm{CP}}=\theta_{2-\mathrm{CP}}=6$, 10 and $10 \mathrm{~s}$ for all films based on PEDOT, PNMPy and PNCPy, respectively.

\section{Preparation of Au colloidal nanoparticles}

Preparation of the AuNPs was performed following the standard procedure described in the literature. ${ }^{30,31}$ All glassware used in such preparation was thoroughly cleaned in aqua regia 
(3:1 $\mathrm{HCl}: \mathrm{HNO}_{3}$ ), rinsed in doubly distilled water, and ovendried prior to use. In a $1 \mathrm{~L}$ round-bottom flask equipped with a condenser, $500 \mathrm{~mL}$ of $1 \mathrm{mM} \mathrm{HAuCl}_{4}$ was brought to a rolling boil with vigorous stirring. Rapid addition of $50 \mathrm{~mL}$ of $38.8 \mathrm{mM}$ sodium citrate to the vortex of the solution produced a color change from pale yellow to burgundy. Boiling was continued for $15 \mathrm{~min}$. After this, the heating mantle was removed while the stirring was continued for $30 \mathrm{~min}$. When the solution reached the room temperature, it was filtered through a $0.2 \mu \mathrm{m}$ membrane filter. The resulting solution of colloidal particles showed an absorption maximum at $520 \mathrm{~nm}$ indicating that the particle size ranged from 9 to $22 \mathrm{~nm}$. A spherical model for a particle size of $13 \mathrm{~nm}$ was used to determine approximately the concentration of mother solution by UV-vis absorption, which was estimated to be 7.4 nM. $^{31}$

\section{Preparation of AuNPs-modified GC electrodes}

Deposition of the AuNPs onto the modified GC electrodes to fabricate 1-CP/AuNP and 2-CP/AuNP composites was performed using a previously used procedure. ${ }^{18}$ More specifically, $4 \mu \mathrm{L}$ of the AuNPs colloidal solution were dropped onto the 1-CP and 2-CP film surface, subsequently drying under atmosphere conditions. The AuNP concentration in the modified electrode surface was determined to be $\sim 23 \times 10^{9}$ nanoparticles $\mathrm{mm}^{-2}$, assuming that all the AuNPs were well adhered to the 1-CP and 2-CP modified GC electrode, since no absorption band at $520 \mathrm{~nm}$ was identified in the electrochemical solution after tests.

\section{Profilometry}

The thickness of the films was determined through profilometry measurements using a profilometer Dektack 6 from Veeco.

\section{Electrochemical measurements for detection of DA}

Electrochemical detection was carried out by cyclic voltammetry (CV) using the Autolab PGSTAT302N equipment described above. All electrochemical experiments were performed in a glass cell containing $10 \mathrm{~mL}$ of $0.1 \mathrm{M}$ PBS $(\mathrm{pH}=7.4)$ at room temperature and equipped with saturated $\mathrm{Ag} \mid \mathrm{AgCl}$ as a reference electrode and platinum $(\mathrm{Pt})$ wire as a counter electrode. Voltammograms were recorded in the potential range from -0.40 to $0.80 \mathrm{~V}$ at a scan rate of $50 \mathrm{mV} \mathrm{s}^{-1}$ unless otherwise the scan rate is explicitly specified. All the modified electrodes were in contact with the electrolyte solution for $5 \mathrm{~min}$ prior to $\mathrm{CV}$ measurements.

\section{FTIR and UV-vis spectroscopies}

FTIR spectra were recorded on a Bruker Vertex 70 FTIR spectrometer, equipped with a diamond ATR device (Golden Gate, Bruker) in transmission mode, by using $\mathrm{KBr}$ pellets.

UV-vis absorption spectra were obtained using a UV-vis-NIR Shimadzu 3600 spectrophotometer equipped with a tungsten halogen visible source, a deuterium arc UV source, a photomultiplier tube UV-vis detector, and a InGaAs photodiode and cooled PbS photocell NIR detectors. Spectra were recorded in the absorbance mode using the integrating sphere accessory (model ISR-3100), the range wavelength being 200-900 $\mathrm{nm}$. The interior of the integrating sphere was coated with a highly diffuse $\mathrm{BaSO}_{4}$ reflectance standard. Single-scan spectra were recorded at a scan speed of $60 \mathrm{~nm} \mathrm{~min}^{-1}$. Measurements, data collection and data evaluation were controlled by the computer software UVProbe version 2.31.

\section{Electrochemical properties}

The electrochemical properties (i.e. electroactivity and stability) of the polymer explicitly designed in this work were determined by cyclic voltammetry using a phosphate buffer saline solution (PBS, $\mathrm{pH}=7.4$ ). The initial and final potentials were $-0.4 \mathrm{~V}$, and the reversal potential was $0.8 \mathrm{~V}$. A scan rate of $50 \mathrm{mV} \mathrm{s}^{-1}$ was used.

\section{Scanning electron microscopy (SEM)}

SEM studies were carried out using a Focused Ion Beam Zeiss Neon40 scanning electron microscope operating at $5 \mathrm{kV}$, equipped with an energy dispersive X-ray (EDX) spectroscopy system. Samples were mounted on a double-sided adhesive carbon disc.

\section{Atomic force miscroscopy (AFM)}

Topographic images were obtained with a Molecular Imaging PicoSPM using a NanoScope IV controller under ambient conditions. The RMS roughness was determined considering a $5 \times 5 \mu \mathrm{m}^{2}$ window size.

\section{Quantum mechanical calculations}

Calculations were performed using the Gaussian $09^{32}$ computer package, applying default thresholds and algorithms. PEDOT was modeled considering small oligomers in the radical cation state (charge $=+1$ and spin multiplicity $=2$ ) made of $n$ repeat units ( $n$-EDOT, with $n$ ranging from 1 to 7 ). DA, AA and UA were considered as oxidized species (Fig. 1): dopamine-o-quinone (DQ),

(a)<smiles>NCCCCCC1=CC(=O)C(=O)C=C1CCN</smiles>

(b)<smiles>[O]C1=C(O)C(=O)OC1C(O)CO</smiles>

(c)

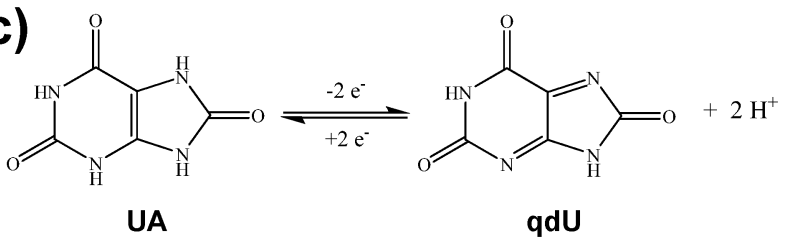

Fig. 1 Electrochemical oxidation reactions for (a) dopamine, (b) ascorbic acid and (c) uric acid. 
dehydroascorbic acid (dAA) and quinoid diimine form (qdU), respectively. The selection of DQ, dAA, qdU and the oxidized oligomers was based on our own experimental results (see the Results and discussion section), which indicate that at the detection potential the oxidation from DA to DQ, AA to dAA, and UA to qdU has occurred and the polymer is oxidized.

The structures of the $n$-EDOT $\cdots \mathrm{DQ}, n$-EDOT $\cdots \mathrm{dAA}$ and $n$-EDOT $\cdots$ qdU complexes were determined by full geometry optimization in the gas-phase at the UB3LYP ${ }^{33,34}$ level using the $6-311++\mathrm{G}(\mathrm{d}, \mathrm{p})$ basis set. ${ }^{35,36}$ The binding energy $\left(\Delta E_{\mathrm{b}}\right)$ was calculated as the difference between the total energy of the optimized complex and the energies of the isolated fragments after optimization. The counterpoise (CP) method $^{37}$ was applied to correct the basis set superposition error from the $\Delta E_{\mathrm{b}}$.

\section{Results and discussion}

\section{Oxidation of DA, AA and UA at 1-CP and 1-CP/AuNP electrodes}

1-CP and 1-CP/AuNPs were electrodeposited potentiostatically on GC electrodes under the experimental conditions described in the Methods section. The thickness of the resulting films, which was estimated by profilometry, was $\sim 0.7 \mu \mathrm{m}$ for 1-PEDOT and $\sim 0.3 \mu \mathrm{m}$ for both 1-PNMPy and 1-PNCPy. This result indicates that GC significantly promotes the polymerization of EDOT monomers, which is a very striking observation. Thus, the thickness of PEDOT films produced using the same experimental conditions (i.e. fixed potential at $1.40 \mathrm{~V}$, acetonitrile solvent and $\mathrm{LiClO}_{4}$ as a supporting electrolyte) and a polymerization time of $5 \mathrm{~s}$ is $\sim 50 \mathrm{~nm}$ when deposited on steel or indium-tin oxide (ITO) electrodes. ${ }^{38}$

The voltammetric behavior of DA in PBS at electrodes modified with PEDOT, PNMPy, PNCPy and their composites with AuNPs was reported in previous studies ${ }^{18-23}$ and, therefore, the comparison between the three modified electrodes has been focused on the selective determination of DA, AA and UA in tertiary mixtures. Fig. 2 shows the voltammograms recorded for the solution mixture with $100 \mu \mathrm{M} \mathrm{DA}, 200 \mu \mathrm{M}$ AA and $100 \mu \mathrm{M}$ UA in $0.1 \mathrm{M}$ PBS at GC electrodes modified with 1-CP or 1-CP/AuNP films. The electrochemical response to the tertiary mixture at bare GC and GC/AuNP electrodes, which is included in Fig. 2, is very poor.

The anodic peak potential $\left(E_{\mathrm{p}}\right)$ for the oxidation of DA at 1-PNMPy electrode is $0.15 \mathrm{~V}$ while the anodic peak intensity $\left(I_{\mathrm{p}}\right)$ associated to such a process is $0.51 \mu \mathrm{A}$. Both $E_{\mathrm{p}}$ and, especially, $I_{\mathrm{p}}$ change significantly when the 1-PNMPy electrode is coated with AuNPs. Thus, the $E_{\mathrm{p}}$ and $I_{\mathrm{p}}$ values for the oxidation of $\mathrm{DA}$ at 1-PNMPy/AuNP are $0.21 \mathrm{~V}$ and $2.50 \mu \mathrm{A}$, respectively. These results are fully consistent with the behavior previously reported for the same electrodes in $0.1 \mathrm{M}$ PBS with $100 \mu \mathrm{M}$ DA (i.e. solution without interferents) ${ }^{18,19}$ The electrocatalytic activity imparted by AuNPs to these electrodes should be attributed to their well-known ability for channeling electrons between the electrode and the electroactive species, promoting better electron transfer between the electrode and the electrolyte. $^{39}$ Thus, AuNPs facilitate the effective charge migration (a)

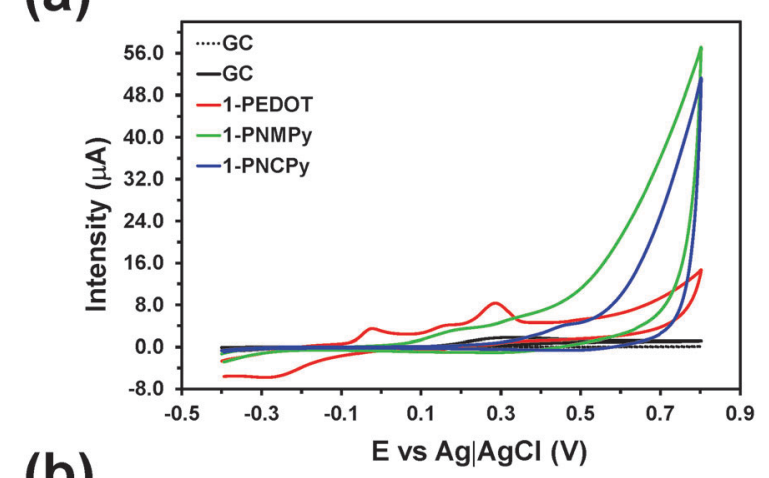

(b)

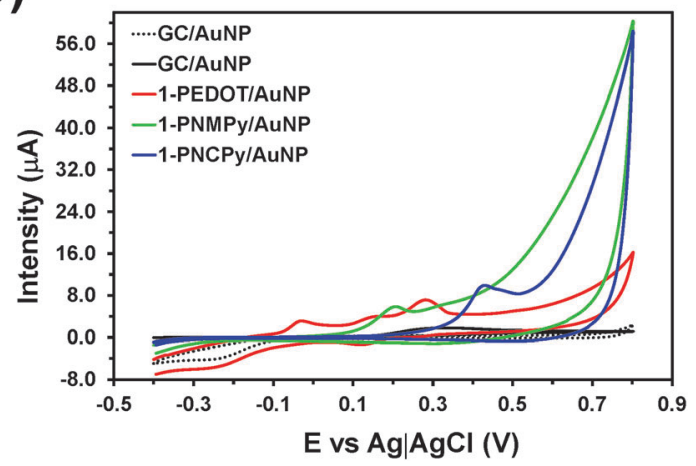

Fig. 2 Control voltammograms of a solution mixture with $100 \mu \mathrm{M} D A$, $200 \mu \mathrm{M} \mathrm{AA}$ and $100 \mu \mathrm{M}$ UA in $0.1 \mathrm{M}$ PBS at (a) 1-CP and 1-CP/AuNP electrodes. The electrochemical response to the same solution mixture (solid black line) and to 0.1 M PBS (dotted black line) at bare (a) GC and (b) GC/AuNP electrodes is also displayed. All voltammograms were obtained by scanning from -0.40 to $0.80 \mathrm{~V}$ at a scan rate of $50 \mathrm{mV} \mathrm{s}^{-1}$.

through the 1-PNMPy films by generating many active sites inside this CP-electrode. Fig. 2 also evidences that, unfortunately, the detection of AA is problematic with 1-PNMPy and 1-PNMPy/ AuNP electrodes since the oxidation peak is inappreciable. Furthermore, the oxidation peaks of DA and UA overlap at PNMPy-containing electrodes making the selective and simultaneous determination of these two species difficult. This behavior does not change when the concentration of analyte is increased (data not shown).

As occurred for 1-PNMPy and 1-PNMPy/AuNP, Fig. 2 and Table 1 indicate that 1-PNCPy and 1-PNCPy/AuNP are not appropriate for the selective detection of the three investigated species. Thus, the oxidation peaks of DA and UA overlap while the oxidation of AA is not detected. Although these results look in opposition with those previously reported for ultra-thin films of PNMPy and PNCPy, ${ }^{19}$ it should be noted that in such work voltammetric assays were performed using a DA solution rather than a tertiary mixture. Furthermore, these results suggest that the efficacy of PNMPy and PNCPy for the detection of DA depends on the thickness of the film, decreasing with increasing thickness. This behavior has been attributed to the fact that the electroactivity of these PPy derivatives is known to decrease with increasing thickness due to both the formation of cross-links and the existence of secondary oxidation processes. ${ }^{28,29}$ 
Table 1 Sensitivity and resolution obtained for the determination of DA, $\mathrm{AA}$ and $\mathrm{UA}$ in $0.1 \mathrm{M}$ PBS using different 1-CP and 1-CP/AuNP electrodes. Cyclic voltammograms are displayed in Fig. 2

\begin{tabular}{lccclll}
\hline & \multicolumn{3}{c}{ Sensitivity $\left(\mu \mathrm{Am}^{-1}\right)$} & & \multicolumn{2}{c}{ Resolution $(\mathrm{V})$} \\
\cline { 2 - 4 } & $\mathrm{DA}$ & $\mathrm{AA}$ & $\mathrm{UA}$ & & AA-DA & UA-DA \\
\hline 1-PEDOT & 4.4 & 10.5 & 39.3 & & 0.179 & 0.130 \\
1-PNMPy & 5.1 & - & 1.0 & & - & 0.166 \\
1-PNCPy & 3.0 & - & 3.0 & & Overlap \\
1-PEDOT/AuNP & 5.3 & 9.1 & 28.8 & & 0.179 & 0.130 \\
1-PNMPy/AuNP & 25.0 & - & 0.3 & & - & 0.101 \\
1-PNCPy/AuNP & 24.8 & - & 24.8 & & - & Overlap
\end{tabular}

In contrast, the oxidation peaks for DA, AA and UA are very well resolved at 1-PEDOT and 1-PEDOT/AuNP electrodes. Amazingly, AuNPs do not exhibit any electrocatalytic activity in this case. Thus, the $E_{\mathrm{p}}$ for oxidation of DA, AA and UA is 0.15 , -0.03 and $0.28 \mathrm{~V}$, respectively, at both 1-PEDOT and 1-PEDOT/ AuNP electrodes. Similarly, the influence of AuNPs in the $I_{\mathrm{p}}$ values is small: $0.44 / 0.53,2.11 / 1.82$ and $3.93 / 2.88 \mu \mathrm{A}$ for the oxidation of DA, AA and UA, respectively, at 1-PEDOT/1-PEDOT/ AuNP. Thus, AuNPs are inefficient for PEDOT, which should be attributed to the excellent electrochemical and electrical properties of this CP. Thus, the intrinsic porous morphology and the linear molecular structure of PEDOT facilitate the transfer of charged species and electrons between the surface and the electrolyte, ${ }^{4-6,27,38}$ the benefits typically provided by AuNPs being ineffective in this case.

Sensitivity and resolution parameters, which have been expressed as the ratio between the peak intensity for the oxidation of the specie and its concentration in the mixture $\left(\mu \mathrm{AmM}^{-1}\right)$ and the difference between the peak oxidation potentials of two species (V), respectively, for the six electrodes investigated in this section are listed in Table 1 . As can be seen, 1-PEDOT and its homolog coated with AuNPs show the highest performance for the selective determination of DA, AA and UA. These electrodes provide separation of the peak potentials and, additionally, present peak currents high enough for unambiguous detection. In contrast, electrodes based on 1-PNMPy and 1-PNCPy, which were found to be very effective for the detection of DA in solutions without interferents, ${ }^{18,19}$ show important disadvantages for the selective determination of DA in real biological fluids.

\section{Oxidation of DA, AA and UA at 2-CP and 2-CP/AuNP electrodes}

In order to examine the effect of the interphase created in 2-layered films on the selective detection of DA, the electrochemical behavior of the solution mixture with $100 \mu \mathrm{M}$ DA, $200 \mu \mathrm{M}$ AA and $100 \mu \mathrm{M}$ UA in $0.1 \mathrm{M}$ PBS was studied at 2-CP and 2-CP/AuNP electrodes. Fig. 3 displays the recorded voltammograms while Table 2 compares the resulting sensitivity and resolution parameters.

The oxidation peaks of the three species are clearly identified in the cyclic voltammograms recorded at 2-PEDOT and 2-PEDOT/AuNP, which are very similar to those displayed in Fig. 2 for 1-PEDOT and 1-PEDOT/AuNP. Thus, the largest effect produced by the interphase created inside PEDOT corresponds (a)

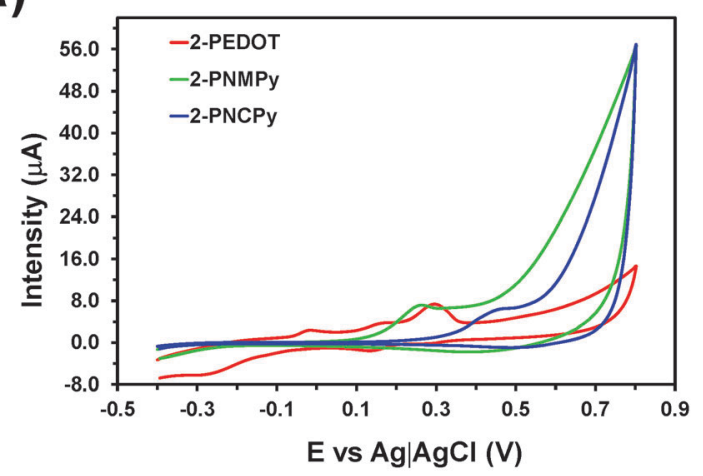

(b)

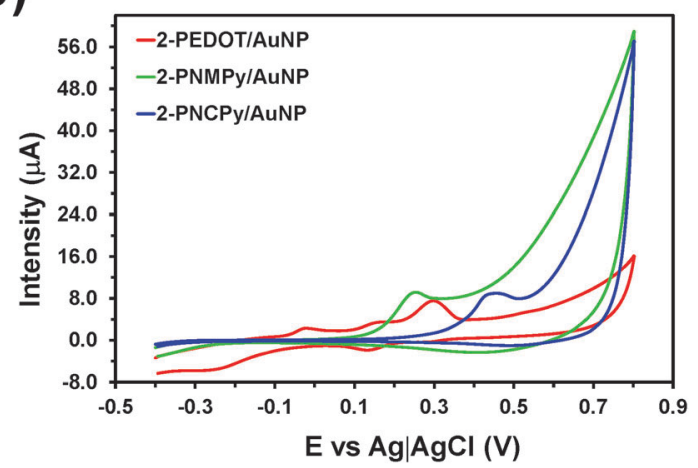

Fig. 3 Control voltammograms of a solution mixture with $100 \mu \mathrm{M} D A$, $200 \mu \mathrm{M} \mathrm{AA}$ and $100 \mu \mathrm{M}$ UA in $0.1 \mathrm{M}$ PBS at (a) 2-CP and (b) 2-CP/AuNP electrodes. All voltammograms were obtained by scanning from -0.40 to $0.80 \mathrm{~V}$ at a scan rate of $50 \mathrm{mV} \mathrm{s}^{-1}$.

Table 2 Sensitivity and resolution obtained for the determination of DA, $\mathrm{AA}$ and UA in $0.1 \mathrm{M}$ PBS using different 2-CP and 2-CP/AuNP electrodes. Cyclic voltammograms are displayed in Fig. 3

\begin{tabular}{lrlllll}
\hline & \multicolumn{3}{c}{ Sensitivity $\left(\mu \mathrm{mM}^{-1}\right)$} & & \multicolumn{2}{c}{ Resolution $(\mathrm{V})$} \\
\cline { 2 - 4 } & \multicolumn{1}{c}{ DA } & AA & UA & & AA-DA & UA-DA \\
\hline 2-PEDOT & 4.6 & 4.6 & 35.1 & & 0.169 & 0.140 \\
2-PNMPy & 15.3 & - & 15.3 & & - & Overlap \\
2-PNCPy & 6.2 & - & 6.2 & & Overlap \\
2-PEDOT/AuNP & 5.3 & 5.6 & 37.6 & & 0.175 & 0.140 \\
2-PNMPy/AuNP & 21.8 & - & 21.8 & & - & Overlap \\
2-PNCPy/AuNP & 17.7 & - & 17.7 & & Overlap
\end{tabular}

to the peak intensity for the oxidation of AA, which decreases from $\sim 10 \mu \mathrm{A}$ to $\sim 5 \mu \mathrm{A}$. The variation of the peak intensity for the oxidation of the other two species is $<23 \%$ while the largest shift in the resolution parameter is $0.010 \mathrm{~V}$. As occurred above for 1-PEDOT films, the influence of AuNPs on the sensitivity and resolution is very small. The overall of these results indicate that ability of PEDOT for the selective determination of DA is due to the intrinsic electrochemical properties of the material. Moreover, such ability remains practically unaltered upon the application of external physical modifications (e.g. AuNP coating and incorporation of an interphase into the film through a two step polymerization process).

Although the interphase enhances the peak intensity for the oxidation of DA and UA at 2-PNMPy and 2-PNCPy, the overlapping 
of the oxidation peaks and the lack of a signal for AA preclude the application of such two CPs for the separation of the species contained in the mixture. Overlapping of the oxidation peaks of DA and UA is also detected at 2-PNMPy/AuNP and 2-PNCPy/ AuNP, in which surface AuNPs cancel the benefit induced by the interphase at the peak intensities. On the other hand, it is worth noting that sensitivity towards DA of 2-PNCPy is significantly higher than that of 1-PNCPy, evidencing an improvement when the film with submicrometric thickness (i.e. $\sim 0.3 \mu \mathrm{m}$ ) transforms into two nanometric layers separated by an interphase.

\section{Modeling the interactions between PEDOT and oxidized DA, AA and UA}

In a recent study quantum mechanical calculations were used to explain the interaction of oxidized DA with PNMPy and PNCPy systems at the molecular level. ${ }^{19}$ For such a purpose, calculations on $n$-NMPy. .DQ and $n$-NCMPy. $\cdots$ DQ complexes, where $n$-NMPy and $n$-NCPy refer to oligomers with $n$ repeat units of NMPy and NCPy, respectively, were carried out considering $n$ values ranging from 1 to 3 . Results indicated that $\mathrm{C}-\mathrm{H} \cdots \mathrm{O}$ non-conventional hydrogen bonds are responsible for the interaction between DQ molecules and these two PPy derivatives play a crucial role in the detection process. ${ }^{19}$

In order to examine the molecular affinity of PEDOT towards DA, AA and UA, quantum mechanical calculations have been used to examine the chemical nature and strength of intermolecular interactions in $n$-EDOT $\cdots \mathrm{X}$ complexes with $\mathrm{X}=\mathrm{DQ}$, dAA and qdU. A build-up scheme, similar to that previously used to model $n$-NMPy $\cdots$ DQ and $n$-NCPy $\cdots$ DQ complexes, ${ }^{19}$ has been applied for such a purpose. Specifically, the interactions between 1-EDOT and DQ, dAA or qdU were examined in the first stage. The resulting structures were used to construct the starting geometries for 3-EDOT $\cdots \mathrm{X}$, which after optimization were employed to build the starting geometries of 5-EDOT $\cdots X$ and 7-EDOT $\cdots \mathrm{X}$.

A total of 29, 38 and 25 starting geometries were constructed for 1-EDOT $\cdots X$ complexes with $\mathrm{X}=\mathrm{DQ}$, dAA and qdU, respectively, considering the different types of intermolecular interactions: conventional and non-conventional hydrogen bonds (i.e. $\mathrm{N}-\mathrm{H} \cdots \mathrm{O}$, $\mathrm{O}-\mathrm{H} \cdots \mathrm{O}, \mathrm{C}-\mathrm{H} \cdots \mathrm{O}$ and $\mathrm{N}-\mathrm{H} \cdots \mathrm{S}$ ), dipole $\cdots \pi$-cloud (i.e. $\mathrm{N}-\mathrm{H} \cdots \pi$ ) and $\pi-\pi$ stacking interactions. From the resulting geometry optimizations, only 6 (DQ), 7 (dAA) and 8 (dqU) structures were considered for the construction of the starting geometries for the corresponding 3-EDOT $\cdots$ X complexes. The remaining optimized structures were discarded due to at least one of the following reasons: (i) they were significantly destabilized with respect to the global minimum showing relative energies $(\Delta E)$ higher than $10 \mathrm{kcal} \mathrm{mol}^{-1}$; or (ii) they were not appropriated for the growing of the $n$-EDOT oligomer (i.e. steric conflicts and/or the elimination of the intermolecular interactions resulted from the enlargement of $n$ from 1 to 3). Regarding the latter, for example some 1-EDOT $\cdots$ DQ structures with $\Delta E \leq 10 \mathrm{kcal} \mathrm{mol}^{-1}$ were stabilized through non-conventional hydrogen bonds between the $\mathrm{C}=\mathrm{O}$ of DQ and one of the $\alpha$-hydrogen atoms of 1-EDOT, the latter disappearing in the polymerization process.
The structures selected for the 1-EDOT $\cdots \mathrm{X}$ complexes were used to construct the starting geometries of 3-EDOT $\cdots \mathrm{X}$ by replacing each $\alpha$-hydrogen atom of 1-EDOT by another EDOT repeat unit. Additionally, new starting geometries in which the analyte interacts simultaneously with two repeat units of 3-EDOT were constructed. The resulting optimized structures (5, 9 and 10 for $\mathrm{X}=\mathrm{DQ}$, dAA and dqU, respectively) were then used to construct the starting geometries of 5-EDOT $\cdots \mathrm{X}$ complexes using the procedure previously described. Geometry optimizations led to 4 (DQ), 7 (dAA) and 6 (qdU) different structures with $\Delta E \leq 1.5 \mathrm{kcal} \mathrm{mol}^{-1}$, which were subsequently used to build the starting geometries of 7-EDOT $\cdots \mathrm{X}$. Optimized structures of 7-EDOT $\cdots$ DQ, 7-EDOT $\cdots$ dAA and 7-EDOT $\cdots$ qdU with $\Delta E \leq 1.5 \mathrm{kcal} \mathrm{mol}^{-1}$ are displayed in Fig. 4a-c, respectively. Furthermore, Table 3 lists the relative energies $(\Delta E)$ and binding energies $\left(\Delta E_{\mathrm{b}}\right)$ of these optimized structures of the three complexes.

The lowest energy structure of 7-EDOT ...DQ, denoted 7Ea/ DQ in Table 3 and Fig. 4a, shows two $\mathrm{C}-\mathrm{H} \cdots \mathrm{O}$ interactions, which involve the $\mathrm{CH}_{2}$ groups located at the dioxane ring of the same EDOT unit and the two $\mathrm{C}=\mathrm{O}$ groups of $\mathrm{DQ}$. The most stable local minimum, 7Eb/DQ, is unfavored by $0.5 \mathrm{kcal} \mathrm{mol}^{-1}$ only. Although this structure also presents two $\mathrm{C}-\mathrm{H} \cdots \mathrm{O}$ interactions, it differs from 7Ea/DQ in the $\mathrm{CH}_{2}$ groups, which belong to consecutive EDOT repeat units. The only difference between the other two structures, 7Ec/DQ and 7Ed/DQ, and the global minimum refers to the relative orientation of the DQ with respect to 7-EDOT. These results corroborate that $\mathrm{C}-\mathrm{H} \cdots \mathrm{O}$ interactions play a crucial role in the detection process of DA, as was suggested in our previous study. ${ }^{19}$ The $\Delta E_{\mathrm{b}}$ of $7 \mathrm{Ea} / \mathrm{DQ}-$ $7 \mathrm{Ed} / \mathrm{DQ}$ structures ranges from -7.5 to $-6.7 \mathrm{kcal} \mathrm{mol}^{-1}$ indicating that despite the identification of two binding sites in each structure, the strength of the interaction between PEDOT and oxidized DA is moderate.

Regarding the interaction between the oxidized AA molecule and the 7-EDOT chain, the lowest energy structure (7Ea/dAA in Fig. $4 \mathrm{~b}$ and Table 3 ) is stabilized by two $\mathrm{C}-\mathrm{H} \cdots \mathrm{O}$ interactions involving consecutive EDOT units. The most stable local minimum, 7Eb/dAA, which also presents two $\mathrm{C}-\mathrm{H} \cdots \mathrm{O}$ interactions involving $\mathrm{CH}_{2}$ groups of consecutive EDOT repeat units, is practically isoenergetic to $7 \mathrm{Ea} / \mathrm{dAA}\left(\Delta E<0.1 \mathrm{kcal} \mathrm{mol}^{-1}\right)$. In both cases, intermolecular interactions involve one $\mathrm{C}=\mathrm{O}$ and one $\mathrm{O}-\mathrm{H}$ group of dAA. The second local minimum, 7Ec/dAA, that is, destabilized $0.9 \mathrm{kcal} \mathrm{mol}^{-1}$ with respect to the global minimum, shows intermolecular interactions between two $\mathrm{C}=\mathrm{O}$ groups of $\mathrm{dAA}$ and $\mathrm{CH}_{2}$ groups located at the dioxane ring of two non-consecutive EDOT repeat units. The $\Delta E_{\mathrm{b}}$ values obtained for 7-EDOT $\cdots$ dAA range from -5.4 to $-2.2 \mathrm{kcal} \mathrm{mol}^{-1}$ (results obtained for structures with $\Delta E>2.0 \mathrm{kcal} \mathrm{mol}^{-1}$ not detailed), evidencing that the strength of the interaction between PEDOT and oxidized AA is weaker than that calculated between the same CP and oxidized DA. This fact may be attributed to the markedly different relative orientation of the analyte and the 7-EDOT chain.

The lowest energy structure of 7-EDOT ‥dqU, 7Ea/dqU (Fig. 4c), is also stabilized by two $\mathrm{C}-\mathrm{H} \cdots \mathrm{O}$ interactions, which involve two 

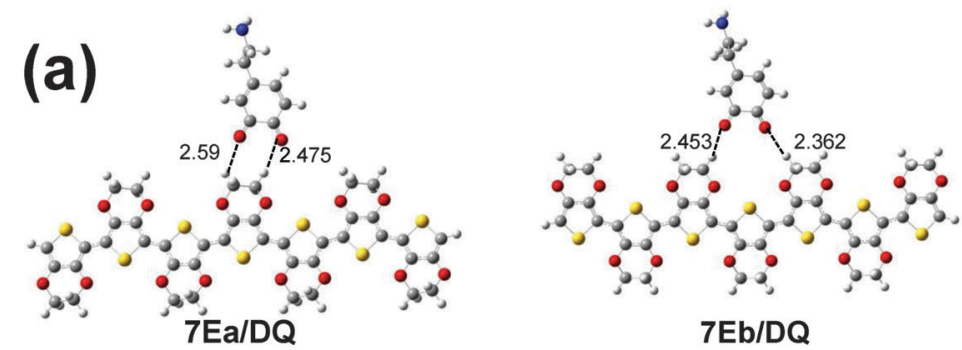

7Eb/DQ
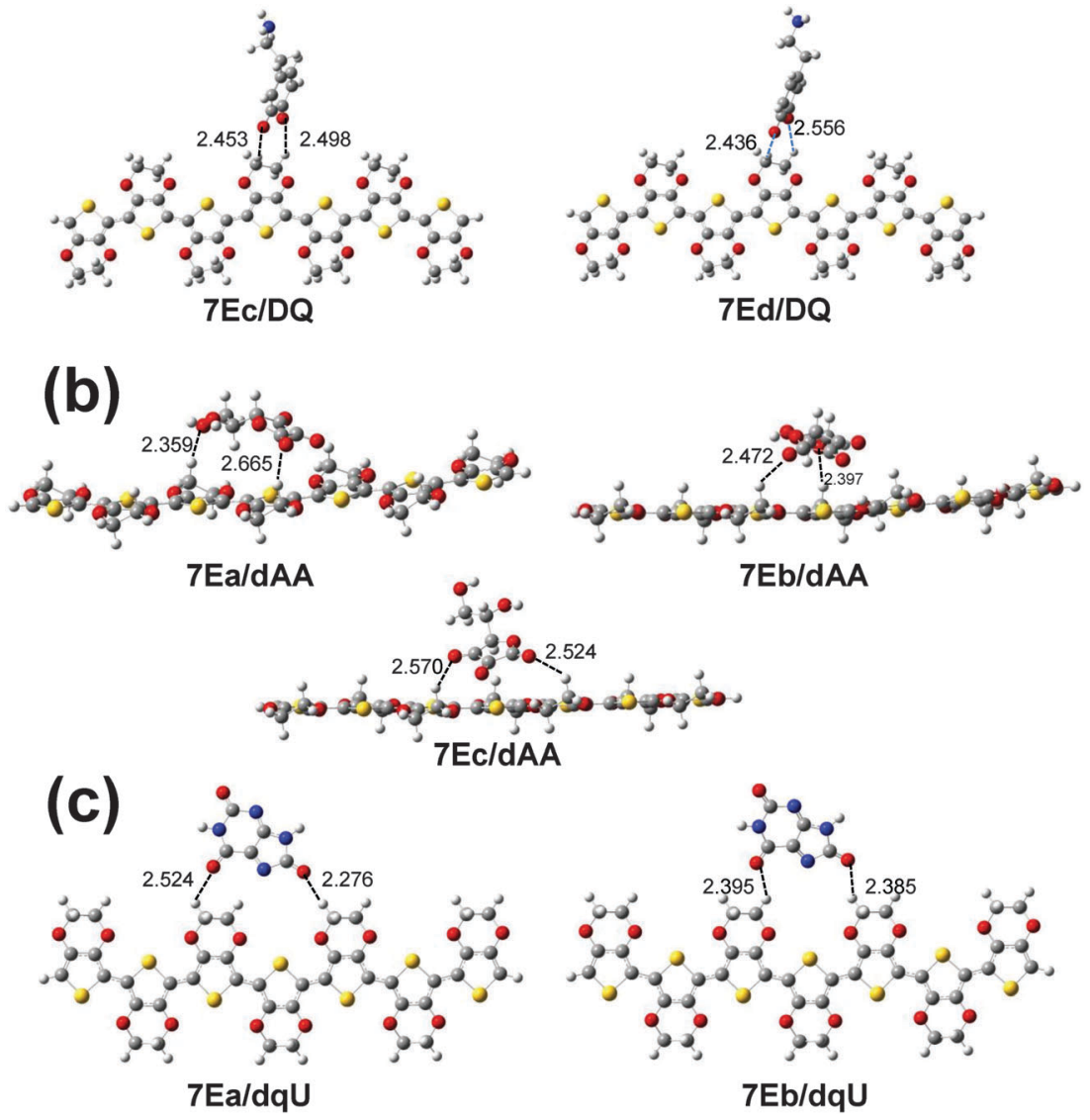

Fig. 4 Optimized structures for (a) 7-EDOT...DQ, (b) 7-EDOT ...dAA and (c) 7-EDOT ...dqU complexes with $\Delta E \leq 1.5 \mathrm{kcal}^{\mathrm{mol}}{ }^{-1}$. Intermolecular $\mathrm{C}-\mathrm{H} \ldots \mathrm{O}$ interactions are indicated. Distances are listed in $\AA$.

Table 3 Relative energy $(\Delta E)$ and binding energy $\left(\Delta E_{\mathrm{b}}\right)$ of the structures of lower energy calculated for 7 -EDOT...X complexes with $X=D Q, d A A$ and qdU. Molecular geometries and energy parameters have been obtained at the B3LYP/6-31++G(d,p) level

\begin{tabular}{llcl}
\hline Complex & Structure & $\begin{array}{l}\Delta E \\
\left(\mathrm{kcal} \mathrm{mol}^{-1}\right)\end{array}$ & $\begin{array}{l}\Delta E_{\mathrm{b}} \\
\left(\mathrm{kcal} \mathrm{mol}^{-1}\right)\end{array}$ \\
\hline 7-EDOT $\cdots$ DQ & 7Ea/DQ & 0.0 & -7.5 \\
& 7Eb/DQ & 0.5 & -7.0 \\
& 7Ec/DQ & 0.7 & -6.9 \\
& 7Ed/DQ & 0.9 & -6.7 \\
7-EDOT $\cdots \mathrm{dAA}$ & 7Ea/dAA & 0.0 & -5.4 \\
& 7Eb/dAA & $<0.1$ & -5.4 \\
& 7Ec/dAA & 0.9 & -4.5 \\
7-EDOT $\cdots$ qdU & 7Ea/qdU & 0.0 & -7.1 \\
& 7Eb/qdU & 0.6 & -6.5
\end{tabular}

$\mathrm{C}=\mathrm{O}$ groups of dqU and two different and non-consecutive EDOT repeat units. The relative orientation of the oxidized UA and the EDOT chain is similar to that showed by 7-EDOT ...DQ minima. Accordingly, the $\Delta E_{\mathrm{b}}$ predicted for $7 \mathrm{Ea} / \mathrm{dqU}\left(-7.1 \mathrm{kcal} \mathrm{mol}^{-1}\right)$ is very close to that calculated for $7 \mathrm{~Eb} / \mathrm{DQ}$ (Table 3). The first local minimum, 7Eb/dqU, is destabilized by only $0.6 \mathrm{kcal} \mathrm{mol}^{-1}$ with respect to $7 \mathrm{Ea} / \mathrm{dqU}$. This structure also presents two $\mathrm{C}-\mathrm{H} \cdots \mathrm{O}$ contacts with alternate EDOT units, the only difference being one $\mathrm{C}-\mathrm{H}$ group. The other structures obtained for 7-EDOT. . dqU present $\Delta E>2.5 \mathrm{kcal} \mathrm{mol}^{-1}$ and $\Delta E_{\mathrm{b}}$ values ranging from -4.4 to $-4.0 \mathrm{kcal} \mathrm{mol}^{-1}$, detailed description being omitted.

Improving the selective detection of DA through rational design

Results displayed in previous sections evidenced that, although the sensitivity of PEDOT towards DA is lower than that of $\mathrm{N}$-substituted PPy derivatives, the former CP is the only one 
able to detect simultaneously DA, AA and UA in tertiary mixtures. Furthermore, the interaction of PEDOT with the oxidized analytes is dominated by $\mathrm{C}-\mathrm{H} \cdots \mathrm{O}$ interactions, involving hydrogen atoms that are not located at the $\pi$-system of the $\mathrm{CP}$. These results suggest that sensitivity of PEDOT towards the three species could be improved by incorporating a substituent able to form intermolecular interactions stronger than $\mathrm{C}-\mathrm{H} \cdots \mathrm{O}$ non-conventional hydrogen bonds. Thus, the grafting of an appropriated polar pendant side group onto the PEDOT backbone is expected to preserve the ability of the latter to separate DA, AA and UA in mixtures and, simultaneously, to produce a significant increase in the tendency to form intermolecular hydrogen bonds.

Within the vast palette of PEDOT derivatives developed in the last decade, ${ }^{40,41}$ those based on the functionalization of the dioxane ring with small and flexible polar substituents are expected to fulfill the already mentioned conditions (i.e. ability to interact with other molecules through conventional hydrogen bonds and to retain the selectivity of PEDOT for the simultaneous detection of DA, AA and UA). Within this context and due to its simplicity, poly(hydroxymethyl-3,4-ethylenedioxythiophene), hereafter abbreviated PHMeDOT (Scheme 2), has been considered to be a suitable candidate for the selective determination of the DA in ternary mixtures. Thus, the electronic characteristics of PEDOT, that are mainly defined by the $\pi$-conjugated system and the oxygen atoms of the dioxane ring, should remain unaltered by the exocyclic hydroxymethyl group, which in turn may easily form intermolecular hydrogen bonds with other species. Another important advantage of PHMeDOT with respect to other PEDOT derivatives is that the experimental conditions required for successful electrochemical polymerization were previously examined. ${ }^{42-45}$

Experimental conditions for the generation of PHMeDOT films were taken from previous studies reported by Roncali and co-workers. ${ }^{42,45}$ Specifically, 1-PHMeDOT films (where by analogy with 1-PEDOT the number one indicates a single polymerization step) was electrodeposited potentiostatically on both ITO and GC electrodes under a constant potential of $1.50 \mathrm{~V}$ using an acetonitrile solution containing $0.1 \mathrm{M}$ monomers with $0.1 \mathrm{M}$ tetrabutylammonium tetrafluoroborate (TBATFB). Replacement of $\mathrm{LiClO}_{4}$, which was used as a supporting electrolyte for the synthesis of PEDOT, by TBATFB was carried out to improve the electrochemical properties of PHMeDOT. ${ }^{42}$ The polymerization time used for the electrodeposition of polymer films on ITO and GC electrodes was $\theta=100$ and $6 \mathrm{~s}$, respectively. The choice of these times was based on the thickness of the films.

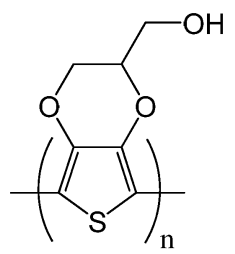

PHMeDOT

Scheme 2
Thus, the thickness of 1-PHMeDOT films, which show dark blue color, deposited on ITO and GC is $\sim 0.8$ and $\sim 0.7 \mu \mathrm{m}$, respectively. These values are consistent with the thickness of 1-PEDOT deposited in GC using $\theta_{1-\mathrm{CP}}=6 \mathrm{~s}$. These results illustrate the significant role of the working electrode on the characteristics of the electrodeposited film. Thus, GC significantly promotes the polymerization of EDOT monomers and its derivatives with respect to steel and ITO substrates. ${ }^{38}$

The FTIR spectra of 1-PHMeDOT and the corresponding monomer, HMeDOT, are displayed in Fig. 5a. The main bands in the spectrum of the monomer are centered at $3215 \mathrm{~cm}^{-1}$ (O-H stretching), $3101 \mathrm{~cm}^{-1}$ (=C-H stretching), $2939 \mathrm{~cm}^{-1}$ (-C-H stretching), $1578 \mathrm{~cm}^{-1}\left(\mathrm{C}=\mathrm{O}\right.$ stretching) and $1484 \mathrm{~cm}^{-1}$

(a)

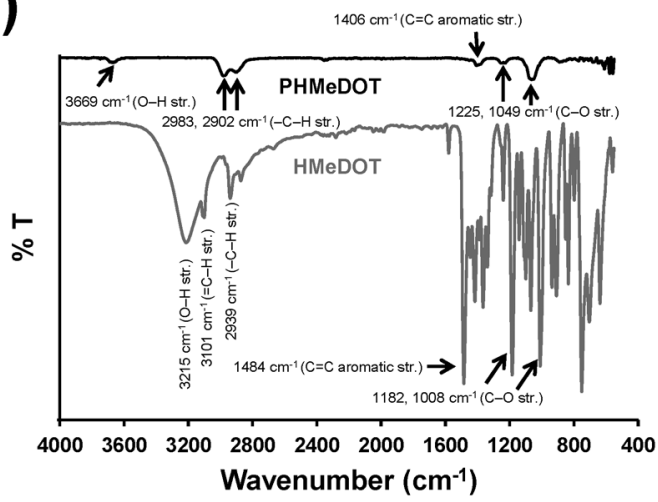

(b)

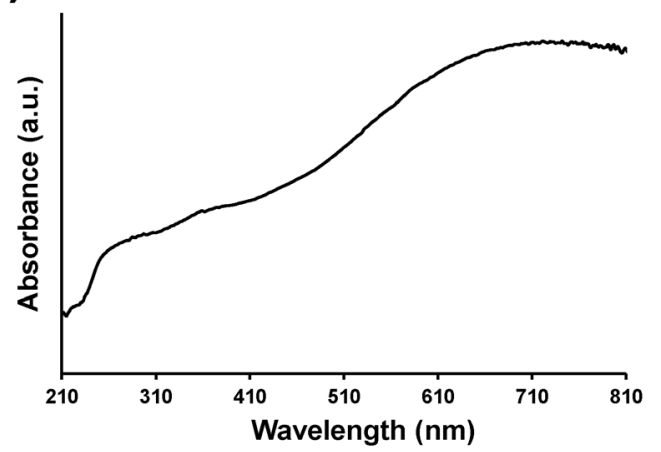

(c)

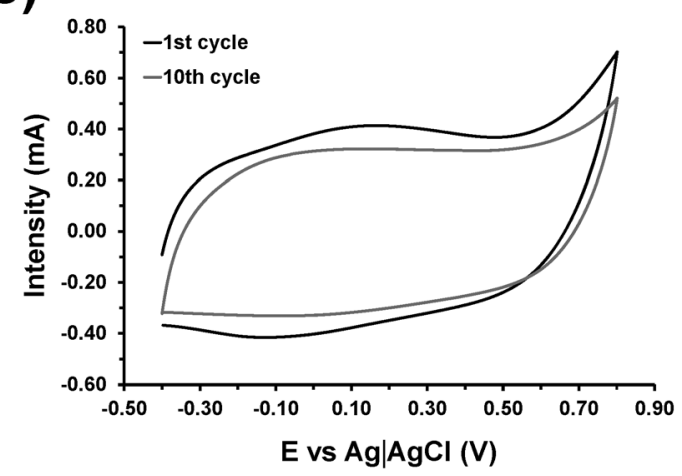

Fig. 5 (a) FTIR spectra of PHMeDOT and HMeDOT. (b) UV-vis spectrum of PHMeDOT electrodeposited on ITO. (c) Voltammograms for PHMeDOT films deposited on ITO after one and ten consecutive oxidation-reduction cycles. Voltammograms were recorded in $0.1 \mathrm{M} \mathrm{PBS}$ at $50 \mathrm{mV} \mathrm{s}^{-1}$ and $25^{\circ} \mathrm{C}$. 
( $\mathrm{C}=\mathrm{C}$ aromatic stretching). The most relevant bands in the 1-PHMeDOT spectrum are observed at $3671 \mathrm{~cm}^{-1}$ (O-H stretching) and $2982 \mathrm{~cm}^{-1}$ (-C-H stretching). Regarding the $\mathrm{O}-\mathrm{H}$ stretching vibration, the red shift observed after polymerization evidences a reduction of intermolecular polymer - . polymer hydrogen bonding associations. ${ }^{46}$ This is expected to facilitate the formation of hydrogen bonds between hydroxyl groups of the polymer and oxidized DA, which would be consistent with the rational design proposed in this study. On the other hand, detailed inspection of the spectrum recorded for the polymer reveals the absence of the absorption band at $3101 \mathrm{~cm}^{-1}$, which is consistent with the absence of hydrogen atoms at the $\mathrm{C}^{\alpha}$-position. This proves that the anodic polymerization of HMeDOT occurs at the $\alpha-\alpha^{\prime}$ position of the thiophene rings, providing linear molecules.

In order to corroborate our initial assumption (i.e. the exocyclic hydroxymethyl group does not provoke important changes in the properties of the material, which are essentially defined by the $\pi$-conjugated backbone), the main properties of PHMeDOT have been evaluated and compared with those reported for PEDOT. Fig. 6a shows SEM micrographs of the typical morphologies found at the surface of 1-PHMeDOT films deposited on ITO. This CP presents a relatively porous cauliflower morphology formed by the aggregation of sticks with fiber-like morphology, giving place to relatively narrow pores with and tortuous channels. This morphology, which is very

(a)

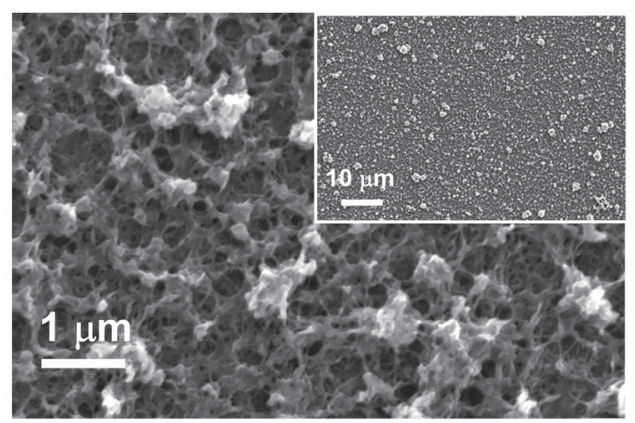

(b)

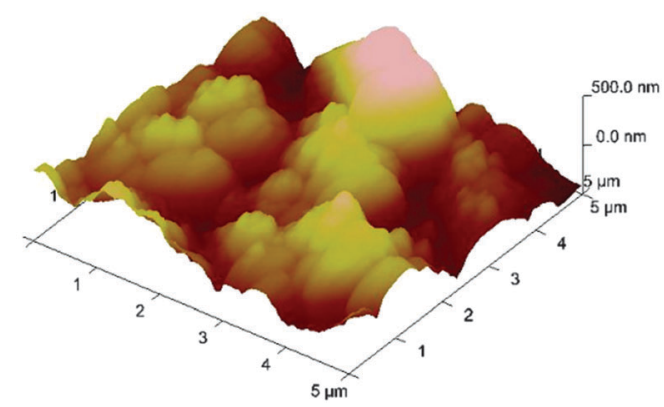

Fig. 6 (a) High and low (inset) resolution SEM micrographs and (b) AFM image of PHMEDOT films electrodeposited on ITO under a constant potential of $1.50 \mathrm{~V}$ using an acetonitrile solution containing 0.1 M HMeDOT and $0.1 \mathrm{M}$ tetrabutylammonium tetrafluoroborate (TBATFB), and a polymerization time $\theta=100 \mathrm{~s}$. similar to that reported for PEDOT, ${ }^{38}$ facilitates the mobility of dopant ions in oxidation and reduction processes (see below). The topology of 1-PHMeDOT films, which is illustrated in the AFM image displayed in Fig. 6b, is fully consistent with the morphology showed in SEM micrographs. Thus, the topology of 1-PHMeDOT can be described as a dense and uniform distribution of clusters that resemble mountains, which in turn are formed by the compact aggregation of a few peaks, separated by narrow valleys. This reflects that the growing of the PHMeDOT chains is accompanied by an aggregation phenomenon, which is in concordance with cauliflower morphology observed by SEM. The RMS roughness of the 1-PHMeDOT films is $r=106 \mathrm{~nm}$, this value being fully consistent with that of 1-PEDOT films obtained using polymerization times of 50 and $300 \mathrm{~s}$ (i.e. 97 and $123 \mathrm{~nm}$, respectively). ${ }^{38}$

The optical properties of 1-PHMeDOT have been analyzed on films deposited on ITO. The UV-vis spectrum displayed in Fig. 5b exhibits an absorption peak at $250 \mathrm{~nm}$ due to $n-\pi$ electronic transitions of the aromatic rings and a broad absorption tail between $\sim 500$ and $\sim 800 \mathrm{~nm}$ ascribed to the polaronic band of the conductive quinoid form. ${ }^{47}$ The optical transitions of 1-PHMeDOT are very similar to those reported for PEDOT and several of its derivatives, which were recently discussed in detail. ${ }^{48,49}$ On the other hand, the intrinsic electrochemical properties of PHMeDOT were examined by CV. Fig. 5c shows the typical control voltammogram in PBS $(\mathrm{pH}=7.4)$, a potential range from -0.40 to $0.80 \mathrm{~V}$ being considered. An anodic peak is detected at $0.15 \mathrm{~V}$, which should be interpreted as the formation of polarons in the polymer chains. The electroactivity refers to the amount of charge reversibly exchanged under the used experimental conditions and, therefore, it increases with the similarity between the anodic and cathodic areas of the control voltammogram. The voltammogram displayed in Fig. $5 \mathrm{c}$ evidences that the electroactivity of 1-PHMeDOT is very high and similar to that reported for 1-PEDOT in the same environment. ${ }^{50}$ Fig. $5 \mathrm{c}$ also includes the voltammogram recorded for the same 1-PHMeDOT film after ten consecutive oxidationreduction cycles, which has been used to evaluate the electrochemical stability. The latter, which decreases with the oxidation and reduction areas of consecutive control voltammograms, has been found to be also very high. Thus, although the electrochemical stability of CPs in PBS is usually moderate or even low, ${ }^{51}$ the loss of electroactivity observed for both 1-PEDOT ${ }^{49}$ and 1-PHMeDOT films after 10 consecutive redox cycles in this physiological environment is only $\sim 8 \%$. The overall results displayed in Fig. 5 and 6 suggest that the properties of 1-PEDOT and 1-PHMeDOT are very similar.

Fig. 7a displays the voltammogram recorded for the solution mixture with $100 \mu \mathrm{M} \mathrm{DA}, 200 \mu \mathrm{M}$ AA and $100 \mu \mathrm{M}$ UA in $0.1 \mathrm{M}$ PBS at 1-PHMeDOT electrodeposited onto GC, the electrochemical response to the tertiary mixture at 1-PEDOT generated using GC being also displayed for comparison. Furthermore, the sensitivity and resolution parameters obtained for such two electrodes are listed in Table 4. Unfortunately, incorporation of the hydroxymethyl substituent does not provoke any improvement in the sensitivity parameters, which are very similar to 
(a)

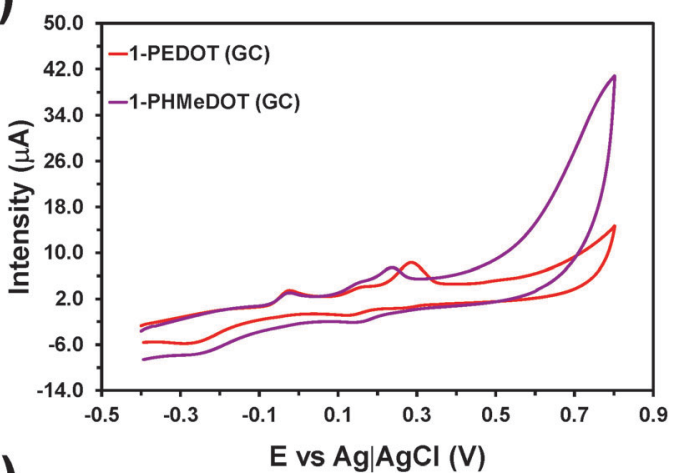

(b)

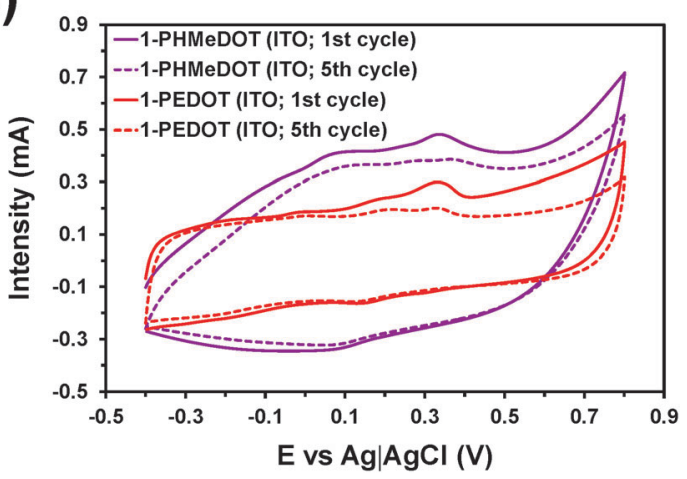

Fig. 7 Control voltammograms of a solution mixture with $100 \mu \mathrm{M}$ DA, $200 \mu \mathrm{M} \mathrm{AA}$ and $100 \mu \mathrm{M} \mathrm{UA}$ in $0.1 \mathrm{M}$ PBS at 1-PEDOT and 1-PHMeDOT deposited on (a) GC and (b) ITO. The electrochemical response to the same solution mixture at the modified ITO electrodes after five consecutive oxidation-reduction cycles is also displayed in (b). All voltammograms were obtained by scanning from -0.40 to $0.80 \mathrm{~V}$ at a scan rate of $50 \mathrm{mV} \mathrm{s}^{-1}$.

Table 4 Sensitivity and resolution obtained for the determination of DA, AA and UA in 0.1 M PBS using 1-PEDOT and 1-PHMeDOT electrodeposited on GC and ITO. Cyclic voltammograms are displayed in Fig. 7

\begin{tabular}{lcrrrrr}
\hline & \multicolumn{3}{c}{ Sensitivity $\left(\mu \mathrm{Am}^{-1}\right)$} & & \multicolumn{2}{c}{ Resolution $(\mathrm{V})$} \\
\cline { 2 - 4 } & \multicolumn{1}{c}{ DA } & \multicolumn{1}{c}{ AA } & UA & & AA-DA & UA-DA \\
\hline 1-PEDOT (GC) & 4.4 & 10.5 & 39.3 & & 0.179 & 0.130 \\
1-PHMeDOT (GC) & 2.7 & 7.4 & 19.1 & & 0.173 & 0.089 \\
1-PEDOT (ITO) & 60.9 & 36.1 & 519.3 & & 0.193 & 0.153 \\
1-PHMeDOT (ITO) & 31.5 & 154.1 & 604.0 & & 0.186 & 0.117 \\
\hline
\end{tabular}

those obtained for 1-PEDOT (with the exception of UA that decreases to $20.2 \mu \mathrm{A} \mathrm{mM}^{-1}$ ). Furthermore, the interactions induced by the new substituent reduce by $46 \%$ the resolution parameter to discriminate between AA and UA. These unexpected results suggested that the favorable synergy between PEDOT chains and the GC substrate decreases upon the incorporation of the hydroxymethyl group to the dioxane ring, which should be attributed to the alterations induced by intermolecular interactions between PHMeDOT chains. In order to corroborate the latter assumption, the voltammetric response of the solution mixture at ITO substrates modified with 1-PEDOT and 1-PHMeDOT was also investigated.

Fig. 7b compares the voltammograms recorded for the solution mixture with $100 \mu \mathrm{M}$ DA, $200 \mu \mathrm{M}$ AA and $100 \mu \mathrm{M}$ UA in $0.1 \mathrm{M}$ PBS at both 1-PHMeDOT and 1-PEDOT deposited on ITO substrates.
The generation of 1-PEDOT film was carried out using experimental conditions identical to those employed for the electrodeposition onto GC (see Methods section) with the exception of the polymerization time, which was $\theta_{1-\mathrm{CP}}=100 \mathrm{~s}$ rather than $\theta_{1-\mathrm{CP}}=6 \mathrm{~s}$. Utilization of ITO substrates provokes that the selective detection of the three species improves upon the incorporation of the hydroxymethyl substituent. This is numerically illustrated in Table 4, which includes the sensitivity and resolution parameters of the two ITO-modified electrodes. It should be emphasized that the sensitivity of the two 1-CPs deposited onto ITO is remarkably higher than observed for the same 1-films deposited onto GC. Furthermore, the sensitivity of 1-PHMeDOT towards oxidized UA and, especially, AA is significantly higher than that of 1-PEDOT, while the former CP is slightly less sensitive towards DQ than the latter one. On the other hand, incorporation of hydroxymethyl groups results in a small approach of the oxidation potentials, the corresponding loss of resolution being relatively unimportant from a practical point of view. Further investigation of the sensitivity evidenced that, as expected, the reduction is practically negligible after five 5 redox cycles. This is reflected in Fig. 7b, which included the voltammograms obtained after five consecutive redox cycles for the 0.1 M PBS solution mixture at both 1-PHMeDOT and 1-PEDOT deposited on ITO substrates.

\section{Conclusions}

The voltammetric behavior of DA-, AA- and UA-containing tertiary mixtures at GC electrodes modified with 1-CP, 1-CP/AuNP, 2-CP and 2-CP/AuNP submicrometric films, where $\mathrm{CP}=\mathrm{PEDOT}$, PNMPy or PNCPy, indicated that PEDOT is most appropriate for the selective determination of low concentrations of such species. Thus, the sensitivity and resolution provided by PEDOT is significantly better than those obtained using PNMPy and PNCPy, which show overlapping of the oxidation peaks of DA and UA. Unfortunately, the performance of PEDOT for the selective detection of DA cannot be improved by adding a coating of AuNPs at the surface or by incorporating interphases inside the film through multiple step polymerization techniques. However, this improvement can be achieved through a rational design strategy oriented to enhance the binding affinity of PEDOT towards the three investigated species.

Quantum mechanical calculations indicate that complexes formed by $n$-EDOT oligomers and the oxidized forms of DA, AA and UA are essentially dominated by $\mathrm{C}-\mathrm{H} \cdots \mathrm{O}$ interactions. This suggests that the sensing abilities of PEDOT may be improved by incorporating substituents able to facilitate the formation of intermolecular hydrogen bonds with such species. For this purpose, PHMeDOT, which incorporates a hydroxymethyl substituent attached to the dioxane ring of every repeat unit, has been synthesized and subsequently characterized. However, the sensitivity and resolution parameters of GC modified with 1-PHMeDOT are worse than those found for GC coated with 1-PEDOT, suggesting that such a substrate promotes the formation of intermolecular interactions between PHMeDOT chains 
through the exocyclic substituent. In contrast, the sensitivity and resolution parameters of both 1-PHMeDOT and 1-PEDOT improve considerably when the CPs are deposited onto ITO surfaces. Moreover, the sensitivities of 1-PHMeDOT towards AA and UA are significantly higher than that of 1-PEDOT, evidencing that intermolecular interactions are stronger in the former than in the latter.

\section{Acknowledgements}

Financial support from the MINECO and FEDER (MAT2012-34498), Generalitat de Catalunya (Research group 2009 SGR 925) is gratefully acknowledged. Support for the research of C.A. was received through the prize "ICREA Academia" for excellence in research funded by the Generalitat de Catalunya. G.F. is thanked for the financial support through a FPI-UPC grant.

\section{References}

1 J. Roncali, Chem. Rev., 1997, 97, 173-206.

2 T. A. Skotheim, R. L. Elsenbaumer and J. R. Reynolds, Handbook of conducting polymers, Marcel Dekker, New York, 1998.

3 R. J. Kline and M. D. McGehee, Polym. Rev., 2006, 46, 27-45. 4 F. Jonas and L. Shrader, Synth. Met., 1991, 83, 141-143.

5 G. Heywang and F. Jonas, Adv. Mater., 1992, 4, 116-118.

6 M. Dietrich, J. Heinze, G. Heywang and F. Jonas, J. Electroanal. Chem., 1994, 369, 87-92.

7 C. J. Brabec, N. S. Sariciftci and J. C. Hummelen, Adv. Funct. Mater., 2001, 11, 15-26.

8 M. Granström, M. Berggren and O. Inganäs, Science, 1995, 267, 1479-1481.

9 L. Groenendaal, F. Jonas, V. Freitag, H. Pielartzik and J. R. Reynolds, Adv. Mater., 2000, 12, 481-494.

10 L. Groenendaal, G. Zotti, P.-H. Aubert, S. M. Waybright and J. R. Reynolds, Adv. Mater., 2003, 15, 855-879.

11 B. Teixeira-Dias, D. Zanuy, J. Poater, M. Solà, F. Estrany, L. J. del Valle and C. Alemán, Soft Matter, 2011, 7, 9922-9932.

12 V. S. Vasantha and S. M. Chen, J. Electroanal. Chem., 2006, 592, 77-87.

13 W. Y. Su and S. H. Cheng, Electrochem. Commun., 2008, 10, 899-902.

14 D. López-Pérez, D. Aradilla, L. J. del Valle and C. Alemán, J. Phys. Chem. C, 2013, 117, 6607-6619.

15 B. Teixeira-Dias, L. J. del Valle, D. Aradilla, F. Estrany and C. Alemán, Macromol. Mater. Eng., 2012, 297, 427-436.

16 L. J. Del Valle, D. Aradilla, R. Oliver, F. Sepulcre, A. Gamez, E. Armelin, C. Alemán and F. Estrany, Eur. Polym. J., 2007, 43, 2342-2349.

17 L. J. Del Valle, F. Estrany, E. Armelin, R. Oliver and C. Alemán, Macromol. Biosci., 2008, 8, 1144-1151.

18 M. Martí, G. Fabregat, F. Estrany, C. Alemán and E. Armelin, J. Mater. Chem., 2010, 20, 10652-10660.

19 G. Fabregat, E. Córdova-Mateo, E. Armelin, O. Bertran and C. Alemán, J. Phys. Chem. C, 2011, 115, 14933-14941.
20 N. F. Atta, A. Galal and E. H. El-Ads, Electrochim. Acta, 2012, 69, 102-111.

21 S. S. Kumar, J. Mathiyarasu and K. L. Phani, J. Electroanal. Chem., 2005, 578, 95-103.

22 N. F. Atta, A. Galal and R. A. Ahmed, Bioelectrochemistry, 2011, 80, 132-141.

23 C. Zanardi, F. Terzi and R. Seeber, Sens. Actuators, B, 2010, 148, 277-282.

24 E. R. Kandel, J. H. Schwartz and T. M. Jessel, Principles of Neural Science, New York, McGraw-Hill, 4th edn, 2000, pp. 207-298.

25 E. K. Richfield, J. B. Penney and A. B. Young, Neuroscience, 1989, 30, 767-777.

26 D. Aradilla, F. Estrany and C. Alemán, J. Appl. Polym. Sci., 2011, 121, 1982-1991.

27 C. Ocampo, R. Oliver, E. Armelin, C. Alemán and F. Estrany, J. Polym. Res., 2006, 13, 193-200.

28 R. Oliver, A. Muñoz, C. Ocampo, C. Alemán, E. Armelin and F. Estrany, Chem. Phys., 2006, 328, 299-306.

29 D. Aradilla, F. Estrany, E. Armelin, R. Oliver, J. I. Iribarren and C. Alemán, Macromol. Chem. Phys., 2010, 211, 1663-1672.

30 R. G. Freeman, M. B. Hommer, K. C. Grabar, M. A. Jackson and M. J. Natan, J. Phys. Chem., 1996, 100, 718-724.

31 S. Link and M. A. El-Sayed, J. Phys. Chem. B, 1999, 103, 8410-8426.

32 M. J. Frisch, G. W. Trucks, H. B. Schlegel, G. E. Scuseria, M. A. Robb, J. R. Cheeseman, G. Scalmani, V. Barone, B. Mennucci, G. A. Petersson, H. Nakatsuji, M. Caricato, X. Li, H. P. Hratchian, A. F. Izmaylov, J. Bloino, G. Zheng, J. L. Sonnenberg, M. Hada, M. Ehara, K. Toyota, R. Fukuda, J. Hasegawa, M. Ishida, T. Nakajima, Y. Honda, O. Kitao, H. Nakai, T. Vreven, J. A. Montgomery Jr., J. E. Peralta, F. Ogliaro, M. Bearpark, J. J. Heyd, E. Brothers, K. N. Kudin, V. N. Staroverov, R. Kobayashi, J. Normand, K. Raghavachari, A. Rendell, J. C. Burant, S. S. Iyengar, J. Tomasi, M. Cossi, N. Rega, J. M. Millam, M. Klene, J. E. Knox, J. B. Cross, V. Bakken, C. Adamo, J. Jaramillo, R. Gomperts, R. E. Stratmann, O. Yazyev, A. J. Austin, R. Cammi, C. Pomelli, J. W. Ochterski, R. L. Martin, K. Morokuma, V. G. Zakrzewski, G. A. Voth, P. Salvador, J. J. Dannenberg, S. Dapprich, A. D. Daniels, O. Farkas, J. B. Foresman, J. V. Ortiz, J. Cioslowski and D. J. Fox, Gaussian 09, revision A.01, Gaussian, Inc., Wallingford, CT, 2009.

33 A. D. Becke, J. Chem. Phys., 1993, 98, 1372-1377.

34 C. Lee, W. Yang and R. G. Parr, Phys. Rev. B: Condens. Matter Mater. Phys., 1988, 37, 785-789.

35 P. C. Hariharan and J. A. Pople, Theor. Chim. Acta, 1973, 28, 213-222.

36 A. D. McLean and G. S. Chandler, J. Chem. Phys., 1980, 72, 5639-5648.

37 S. F. Boys and F. Bernardi, Mol. Phys., 1970, 19, 553-566.

38 D. Aradilla, F. Estrany, E. Armelin and C. Alemán, Thin Solid Films, 2012, 520, 4402-4409.

39 R. N. Goyal, V. K. Gupta, M. Oyama and N. Bachheti, Talanta, 2007, 72, 976-983. 
40 J. Roncali, P. Blanchar and P. Frère, J. Mater. Chem., 2005, 15, 1589-1610.

41 D. Demeter, T. Rousseau and J. Roncali, RSC Adv., 2013, 3, 704-707.

42 S. Akoudad and J. Roncali, Electrochem. Commun., 2000, 2, 72-76.

43 Y. Xiao, X. Cui, J. M. Hancock, M. Bouguettaya, J. R. Reynolds and D. C. Martin, Sens. Actuators, B, 2004, 99, 437-443.

44 Y. Shi, S.-C. Luo, W. Fang, K. Zhang, E. M. Ali, F. Y. C. Boey, J. Y. Ying, J. Wang, H.-h. Yu and L.-J. Li, Org. Electron., 2008, 9, 859-863.

45 H. Brisset, A.-E. Navarro, C. Moustrou, I. Perepichka and J. Roncali, Electrochem. Commun., 2004, 6, 249-253.
46 J. Casanovas, O. Bertran, E. Armelin, J. Torras, F. Estrany and C. Alemán, J. Phys. Chem. A, 2008, 112, 10650-10656.

47 S. Garreau, G. Louarn, J. P. Buisson, G. Froyer and S. Lefrant, Macromolecules, 1999, 32, 6807-6812.

48 G. Fabregat, G. Ballano, J. Casanovas, A. D. Laurent, E. Armelin, L. J. del Valle, C. Cativiela, D. Jacquemin and C. Alemán, RSC Adv., 2013, 3, 21069-21083.

49 G. Fabregat, G. Ballano, E. Armelin, L. J. del Valle, C. Cativiela and C. Alemán, Polym. Chem., 2013, 4, 1412-1424.

50 L. J. del Valle, D. Aradilla, R. Oliver, F. Sepulcre, A. Gamez, E. Armelin, C. Alemán and F. Estrany, Eur. Polym. J., 2007, 43, 2342-2349.

51 M. M. Pérez-Madrigal, E. Armelin, L. J. del Valle, F. Estrany and C. Alemán, Polym. Chem., 2012, 3, 979-991. 